\title{
Kinetics of Apatite Deposition of Silica Gel Dependent on the Inorganic Ion Composition of Simulated Body Fluids
}

\author{
Kanji TSURU, Masaaki KUBO, Satoshi HAYAKAWA, Chikara OHTSUKI* and Akiyoshi OSAKA \\ Biomaterials Lab., Faculty of Engineering, Okayama University, 3-1-1, Tsushima-Naka, Okayama-shi 700-8530 \\ *NAIST, 8916-5, Takayama-cho, Ikoma-shi 630-0101 \\ シリカゲルのアパタイト形成速度に及ぼす擬似体液中の無機イオンの影響 \\ 都留寛治·久保正明·早川 聡·大槻主税*·尾坂明義 \\ 岡山大学工学部生物機能工学科, 700-8530 岡山市津島中 3-1-1 \\ *奈良先端科学技術大学院大学, 630-0101 生駒市高山町 8916-5
}

\begin{abstract}
Nucleation and crystal growth mechanism of apatite formation on porous silica gel derived by a sol-gel procedure was investigated by the use of several simulated body fluids (SBF's) that had different concentrations of $\mathrm{Ca}(\mathbb{I I}), \mathrm{P}(\mathrm{V})$, and $\mathrm{OH}^{-}$but had the same degree of supersaturation for hydroxyapatite. Induction time of apatite crystallization in SBF's was evaluated by thin film X-ray diffractometry. The effect of each ion on the induction time increased in the order: $\mathrm{Ca}(\mathrm{II})$-rich $\mathrm{SBF}<\mathrm{P}(\mathrm{V})$-rich $\mathrm{SBF} \ll \mathrm{OH}^{-}$-rich SBF, while that for the rate of initial crystal gxowth of apatite increased in the order: $\mathrm{P}(\mathrm{V})$-rich $\mathrm{SBF}<\mathrm{Ca}(\mathrm{II})$-rich $\mathrm{SBF}<$ $\mathrm{OH}^{-}$-rich SBF. It suggested that amorphous calcium phosphate (ACP) deposited as the precursor of apatite and $\mathrm{ACP}$ transformed into apatite nuclei by the incorporation of $\mathrm{OH}^{-}$. Moreover, the transformation was accelerated by large amount of $\mathrm{ACP}$ and was assisted by the rearrangement of silicate units in the gel surface. $\mathrm{Ca}$ (III) was richer in $\mathrm{ACP}$ deposited in $\mathrm{Ca}$ (II) -rich $\mathrm{SBF}$ and $\mathrm{OH} \mathrm{H}^{-}$-rich $\mathrm{SBF}$ than that deposited in $\mathrm{P}(\mathrm{V})$-rich SBF. Ca(II)=rich ACP was favorable for crystal growth.
\end{abstract}

[Received November 20, 2000; Accepted January 24, 2001]

Key-words : Porous silica gel, Apatite, Nucleation, Crystal growth, Supersaturated solution, Sol-gel process, ACP

\section{Introduction}

Bioactive materials like silicate glasses and glass ceramics of specific compositions can bond to living bone tissues as they spontaneously deposit an apatite layer at the interface between the materials and the bone tissue under a body environment. Some of them ${ }^{1), 2}$ have already been employed in clinics. The degree of bioactivity was studied mostly as a function of composition ${ }^{3)}$ in in vitro experiments using simulated body fluids (SBF). Among such fluids prepared until now, that of the Kokubo recipe ${ }^{4}$ ) was most convenient and most frequently used because of the better reproducibility of the in vivo behavior of the materials in in vitro experiments. That is, in Kokubo's SBF those bioactive ceramics yielded a layer of hydroxy carbonate apatite (HCA) that was similar in composition and structure to the mineral phase of bone ${ }^{5), 6)}$ or to HCA formed on them in the body. ${ }^{7)} \mathrm{A}$ mechanism of in vivo and in vitro apatite formation was proposed $^{8}$ where both silanol groups and $\mathrm{Ca}$ (II) dissolved from the materials were the essential factors. Thus the supersaturation or ion concentration of SBF should affect significantly on the biomimetic deposition of apatite. However, only few reports were concerned with the effects of ions in SBF. Li et al. concluded $^{9}$ that the increase in calcium, phosphate, and hydroxide ion concentration accelerated apatite formation, whereas the magnesium ion inhibited apatite formation. Damen and Cate found ${ }^{10}$ that the addition of 0.5 $\mathrm{mmol} / 1 \mathrm{SiO}_{2}$ accelerated the precipitation of calcium phosphate from the supersaturated solutions they employed. In spite of those studies, $\left.\left.{ }^{5)}-7\right), 9\right), 10$ ) the current understanding of the mechanism is not satisfactory yet: they were mostly phenomenological studies, and neither the effects of the ion composition of the surrounding body fluid have been well clarified nor thorough analysis of the nucleation and growth of apatite has been carried out yet. Therefore, the apatite crystallization is worth studying in detail in order to provide the bioactive materials so far developed with enhanced bioactivity or to develop new biomedical materials.

When a crystal is precipitated from a supersaturated solution, the driving force for the crystallization is the difference in Gibbs free energy, $\Delta G$, due to change from a supersaturated solution to a saturated one. A short analysis of $\Delta G$ will derive that the rate of nucleation and crystal growth is described as a function of only calcium, phosphate and hydroxide ion concentrations. $\Delta G$ is expressed as: $-\Delta G=R T \ln (\mathrm{IAP} / \mathrm{Kso})^{1 / v}$

where IAP is the Ionic Activity Product in the supersaturated solution, Kso is the solubility product of hydroxyapatite $\left(5.5 \times 10^{-118}\right)^{11)}$ or the value of IAP at equilibrium, and $v$ is the number of ions in one formula ( $v$ is 18 in hydroxyapatite). In the case of hydroxyapatite deposition, IAP of the solution is represented by Eq. (2).

$$
\begin{aligned}
& \mathrm{IAP}=\left(\gamma_{\mathrm{Ca}^{2-}}\right)^{10}\left[\mathrm{Ca}^{2+}\right]^{10} \times\left(\gamma_{\mathrm{PO}^{3-}}\right)^{6}\left[\mathrm{PO}_{4}{ }^{3-}\right]^{6} \\
& \quad \times\left(\gamma_{\mathrm{OH}^{-}}\right)^{2}\left[\mathrm{OH}^{-}\right]^{2}
\end{aligned}
$$

Here, $\gamma^{\prime}$ s are the activity coefficients and are given in the literature. ${ }^{12)}$ The dissociation constants of the phosphate ions and relevant calcium phosphates are also cited from the literature. ${ }^{11)}$ Letting $S$ denote IAP/Kso, or the degree of supersaturation, Eqs. (3) and (4) represent the rates of nucleation $R_{\mathrm{n}}$ and crystal growth $R_{\mathrm{g}}{ }^{11)}$ in terms of $S$, respectively.

$$
\begin{aligned}
& R_{\mathrm{n}}=k_{\mathrm{n}}(\ln S)^{-2} \\
& R_{\mathrm{g}}=k_{\mathrm{gs}}(S-1)^{n}
\end{aligned}
$$

where $k_{\mathrm{n}}$ and $k_{\mathrm{g}}$ are the constants for nucleation and crystal growth, $s$ is a function of the total number of available growth sites, and $n$ is the effective order of reaction. Since Kso is a constant, Eqs. (1) and (2) show that the $R_{\mathrm{n}}$ and $R_{\mathrm{g}}$ of hydroxyapatite are interpreted by only calcium, phosphate, and hydroxide ion concentration.

In the present study, several SBF's were prepared to have different calcium, phosphate, and hydroxide ion concentrations with keeping the value of $S$ constant so that the same nucleation and crystal growth rate could be expected. When the induction time is defined as the period before a detecta- 
ble amount of apatite nuclei forms, it can be a measure of $R_{\mathrm{n}}$. We derived the induction time from the changes in the peak area of thin film X-ray diffraction (TF-XRD). $R_{\mathrm{g}}$ was represented by the rate of increase in the area of a specific TF-XRD peak. If either of $R_{\mathrm{n}}, R_{\mathrm{g}}$, or the chemical composition of the deposits are dependent on the concentration of a specific ion, the present analysis can give insight into the mechanisms of apatite nucleation and crystal growth in detail. Note that, for such fundamental investigation of apatite deposition, the substrates should not contain alkali and alkaline earth ions because the hydrolysis of - Si-OR (R: alkali and alkaline earth metal) bonds, for example, would increase $\mathrm{pH}$ of SBF very much and affects the deposition of apatite. As the HCA layer was formed on a silica gel in $\mathrm{SBF},{ }^{13)}$ silica gel is one of the most appropriate for this purpose. It is also noted that, for the analysis of structure of silica gel, the use of SBF was avoided and a saline solution was employed since apatite depositing disturbed the analysis.

\section{Experimental}

2.1 Preparation of porous silica gel

Porous silica gel was prepared after Nakanishi ${ }^{9), 14)}$ using tetraethoxysilane, poly (ethyleneglycol), distilled water, and nitric acid. Procedure was described in detail in the literature. ${ }^{14)}$ Specific surface area and pore size distribution were measured with a nitrogen adsorption pore size analyzer (GEMINI 2370, Micromeritics, Tokyo).

2.2 In vitro evaluation of apatite deposition

The porous silica gel blocks were shaped with emery paper into about $10 \times 10 \times 1 \mathrm{~mm}$ in size. SBF of the Kokubo recipe $^{4)}$ was taken as the standard SBF, and denoted as "std-SBF." The fluid contains the same inorganic components as the human blood plasma in similar concentrations as shown in Table 1. The value of IAP for std-SBF is $10^{-96.6}$. SBF's rich in respective ions such as calcium, phosphate, and hydroxide ions were prepared so as to have a fixed value of IAP $\left(=10^{-95}\right)$, as shown in Table 1 . They were denoted as "Ca-SBF", "P-SBF", and "pH-SBF", respectively. Although all SBF's were already in supersaturation against hydroxyapatite, Ca-SBF, $\mathrm{P}-\mathrm{SBF}$, and $\mathrm{pH}-\mathrm{SBF}$ had a larger supersaturation ratio than std-SBF.

The gel specimens were soaked in such an appropriate amount of those SBF's as to attain $10 \mathrm{ml} / \mathrm{m}^{2}$ in the ratio of the SBF volume to the specimen surface area derived from specific surface area. After being soaked, the specimens were gently rinsed with distilled water and dried at room temperature. In the course of soaking, SBF's were not exchanged. Then, as apatite deposited, the component ions were exhausted. The present author believed that such situation should well differentiate the ability of each SBF to induce apatite deposition.

TF-XRD patterns were taken with an X-ray diffractome- ter (RAD-IIA, Cu K $\alpha$, Rigaku, 40 kV, $20 \mathrm{~mA}$ ) attached with a thin-film diffraction apparatus for glancing angle $1^{\circ}$. The surface texture of the specimens before and after soaking for $5 \mathrm{~d}$ were also observed with a scanning electron microscope (SEM, JMSM-6300, JEOL). Fourier-transform infrared (FT-IR) absorption spectra were measured for the specimens before and after soaking in SBF's for $6 \mathrm{~d}$ with a FT-IR spectrometer (Model FT-IR300, JASCO) at a $4 \mathrm{~cm}^{-1}$ resolution. Then the difference spectra were derived by subtracting the FT-IR absorption spectrum of the as-prepared sample from the spectra of the samples after soaking. The $\mathrm{Ca}(\mathrm{II}), \mathrm{Si}(\mathrm{IV})$, and $\mathrm{P}(\mathrm{V})$ concentrations of SBF's before and after soaking were measured by inductively coupled plasma automatic emission spectroscopy (ICP-AES, SPS7700, SEIKO).

2.3 Surface structure after soaking in saline solution

When soaked in SBF's the structural rearrangement and apatite deposition take place at the same time, which results in complicated ${ }^{29} \mathrm{Si} \mathrm{NMR} \mathrm{spectra} \mathrm{and} \mathrm{in} \mathrm{difficulty} \mathrm{to} \mathrm{analyze}$ the structure change. Then, the specimens soaked in a saline solution (0.142 M NaCl, $\mathrm{pH} 7.4)$ for 1-7 d were gently washed with distilled water and dried at $60^{\circ} \mathrm{C}$. A part of them was then pulverized to $<1 \mathrm{~mm}$ in size for the NMR spectra and pore size distribution measurements.

The ${ }^{29} \mathrm{Si}$ NMR spectra were recorded at $7.05 \mathrm{~T}$ (tesla) on a Varian UNITY INOVA300 FT-NMR spectrometer, equipped with a $\mathrm{CP}$ (cross polarization) /MAS (magic angle spinning) probe, under the ${ }^{1} \mathrm{H}-{ }^{29} \mathrm{Si} \mathrm{CP}-\mathrm{MAS}$ and ${ }^{1} \mathrm{H}$ decoupling techniques. The specimens were placed in a zirconia sample tube. The sample spinning speed at the magic angle to the eternal field was $3.5 \mathrm{kHz}$. The ${ }^{29} \mathrm{Si} \mathrm{CP}-\mathrm{MAS}$ NMR spectra were taken at $59.6 \mathrm{MHz}$ with $6.0 \mu \mathrm{s}(\pi / 2)$ pulses, $10 \mathrm{~s}$ recycle delays. The signals from about 1000 pulses were accumulated. The chemical shift was represented in $\delta(\mathrm{ppm})$ by convention. Polydimethylsilane (PDMS: $\delta=-34.0 \mathrm{ppm}$ against tetramethylsilane: $\delta=0 \mathrm{ppm}$ ) was used as the secondary external reference. Pore distribution was also measured with a nitrogen adsorption pore size analyzer (GEMINI 2370).

\section{Results}

\subsection{Calcium phosphate deposition}

Figure 1 (a) shows the fracture surface of the sample before soaking in SBF's. Figs. 1(b), (c), and (d) show the sample surfaces exposed to $\mathrm{Ca}_{-}, \mathrm{P}-$, and $\mathrm{pH}-\mathrm{SBF}$ for $5 \mathrm{~d}$, respectively. Spherical apatite particles were observed on all samples except those soaked in std-SBF (not shown here). As the samples were soaked, ion concentration of SBF's changed. Figure 2(a) shows the increase in $\mathrm{Si}$ (IV) due to the dissolution of $\mathrm{HSiO}_{3}{ }^{-}$from the samples and that the amount of $\mathrm{Si}$ (IV) was independent of the fluids.

Figures 2(b) and (c) show the decrease in $\mathrm{Ca}(\mathrm{II})$ and $\mathrm{P}$

Table 1. Ion Concentration of Several Kinds of Modified Simulated Body Fluids and Human Blood Plasma

\begin{tabular}{lcccccccc}
\hline & \multicolumn{7}{c}{ In concentration $(\mathrm{mM})$} \\
\cline { 2 - 9 } & $\mathrm{Na}^{+}$ & $\mathrm{K}^{+}$ & $\mathrm{Mg}^{2+}$ & $\mathrm{Ca}^{2+}$ & $\mathrm{HCO}_{3}{ }^{-}$ & $\mathrm{HPO}_{4}{ }^{2-}$ & $\mathrm{SO}_{4}{ }^{2-}$ & $\mathrm{pH}$ \\
\hline Blood plasma & 142.0 & 5.0 & 1.5 & 2.5 & 27.0 & 1.0 & 0.5 & 7.4 \\
std-SBF & 142.0 & 5.0 & 1.5 & 2.5 & 4.2 & 1.0 & 0.5 & 7.25 \\
Ca-SBF & 142.0 & 5.0 & 1.5 & 3.7 & 4.2 & 1.0 & 0.5 & 7.25 \\
P-SBF & 142.0 & 5.0 & 1.5 & 2.5 & 4.2 & 1.9 & 0.5 & 7.25 \\
pH-SBF & 142.0 & 5.0 & 1.5 & 2.5 & 4.2 & 1.0 & 0.5 & 7.42 \\
\hline
\end{tabular}



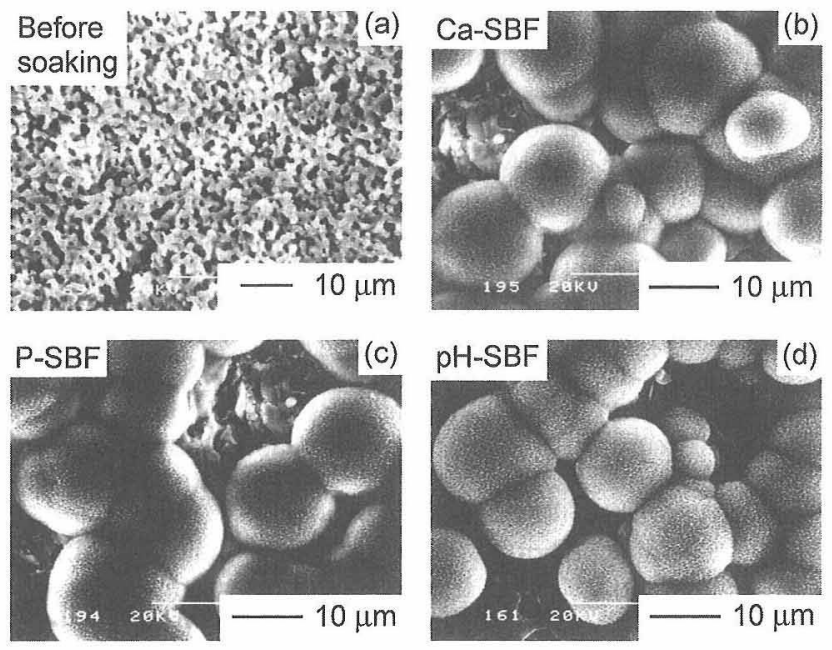

Fig. 1. (a) Fracture surface of the silica gel before soaking. After $5 \mathrm{~d}$ soaking (b) in Ca-SBF, (c) in P-SBF, (d) in pH-SBF. Semispherical agglomerates of apatite were observed on the surface.

(V) concentrations, respectively. The decrease was due to the precipitation or adsorption of some calcium phosphates (including apatite) on the samples, and highly depended on the fluids. Thus calcium phosphate vigorously deposited in Ca-SBF and P-SBF within $12 \mathrm{~h}$, whereas $\mathrm{pH}-\mathrm{SBF}$ required a longer period to be deposit apatite than Ca-SBF and P-SBF. The curve profiles for $\mathrm{Ca}(\mathrm{II})$ and $\mathrm{P}(\mathrm{V})$ for an $\mathrm{SBF}$ were very similar to each other. Those for $\mathrm{pH}-\mathrm{SBF}$ were much different from those for the others, showing only a little decrement at the first stage in $\mathrm{Ca}$ (II) and $\mathrm{P}(\mathrm{V})$ followed by a sudden greater decrement at the 3rd day in a similar manner to that for Ca-SBF and P-SBF. That is, the rate of nucleation and crystal growth depended differently on the increase in ion concentration. This was also confirmed by Fig. 3 showing the TF-XRD patterns of the samples after soaking in each SBF. Apatite formed within $1 \mathrm{~d}$ in Ca-SBF and P-SBF, and within $3 \mathrm{~d}$ in $\mathrm{pH}-\mathrm{SBF}$, while apatite did not formed within $14 \mathrm{~d}$ in std-SBF. The inability of std-SBF to induce apatite crystallization could be attributed to the fact that std-SBF had a smaller value of IAP than the other SBF's.

Figure 4 shows the $\mathrm{Ca} / \mathrm{P}$ ratio of the precipitation on the samples derived from Figs. 2(b) and (c). Ca-SBF showed a hump in the curve indicating $\mathrm{Ca}$ (II) was rich in the phase deposited in an early stage. Even greater hump was indicated for pH-SBF. It should be taken into account, however, that the decrease in $\mathrm{Ca}(\mathrm{II})$ and $\mathrm{P}(\mathrm{V})$ was so small for $\mathrm{pH}$ SBF that only a little fluctuation lead to significant changes. Still it was valid that, within $3 \mathrm{~d}$ soaking, the precipitation from $\mathrm{Ca}-\mathrm{SBF}$ and $\mathrm{pH}-\mathrm{SBF}$ was rich in $\mathrm{Ca}$ (II), and in contrast, that from $\mathrm{P}-\mathrm{SBF}$ was poorer in $\mathrm{Ca}$ (II). In $7 \mathrm{~d}$ soaking in SBF's, the $\mathrm{Ca} / \mathrm{P}$ ratios were converged to about 1.7 , which agreed well with the stoichiometric $\mathrm{Ca} / \mathrm{P}$ ratio of apatite, 1.67.

Figure 5 shows the difference FT-IR spectra of the samples after soaked in SBF's for 6 d. The peak at 1455-1457 $\mathrm{cm}^{-1}$ detected for the samples soaked in $\mathrm{Ca}_{-}, \mathrm{P}-$, and $\mathrm{pH}-$ SBF was assignable to carbonate ions. ${ }^{15)}$ The mineral phase of bone contains carbonate apatite, ${ }^{7)}$ thus the present porous silica gel was confirmed also to induce biomimetic apatite deposition.

\subsection{Gel structure}

Figure 6 shows the ${ }^{29} \mathrm{Si}$ CP-MAS-NMR spectra of the samples before and after soaking in the saline for 1 and $7 \mathrm{~d}$. The resonances at $-92,-100$, and $-110 \mathrm{ppm}$ have been attributed to unit $Q^{2}\left(=\mathrm{Si}\left(\mathrm{OSi}_{2}\left(\mathrm{O}^{-}\right)_{2}\right), Q^{3}\left(=\mathrm{Si}(\mathrm{OSi})_{3}-\right.\right.$ $\left.\mathrm{O}^{-}\right)$, and $Q^{4}\left(=\mathrm{Si}(\mathrm{OSi})_{4}\right)$, respectively. ${ }^{16), 17)}$ All spectra were deconvoluted into three Gaussian functions on the basis of least-mean-square fitting. The results were summarized in Table 2. After soaking for $1 \mathrm{~d}$, the fraction of unit $Q^{3}$ increased at the expense of $Q^{4}$. However, no further changes in the fractions were observed up to $7 \mathrm{~d}$.

Figure 7 shows the changes in the total pore volume as well as the volume of mesopores $(2-200 \mathrm{~nm})$ and nanopores $(<2 \mathrm{~nm})$ due to soaking the samples in the saline for 1,3 , and $7 \mathrm{~d}$. Their specific surface area was $433 \mathrm{~m}^{2} / \mathrm{g}$ and the total pore volume was $0.28 \mathrm{~cm}^{3} / \mathrm{g}$. The fraction of nano-
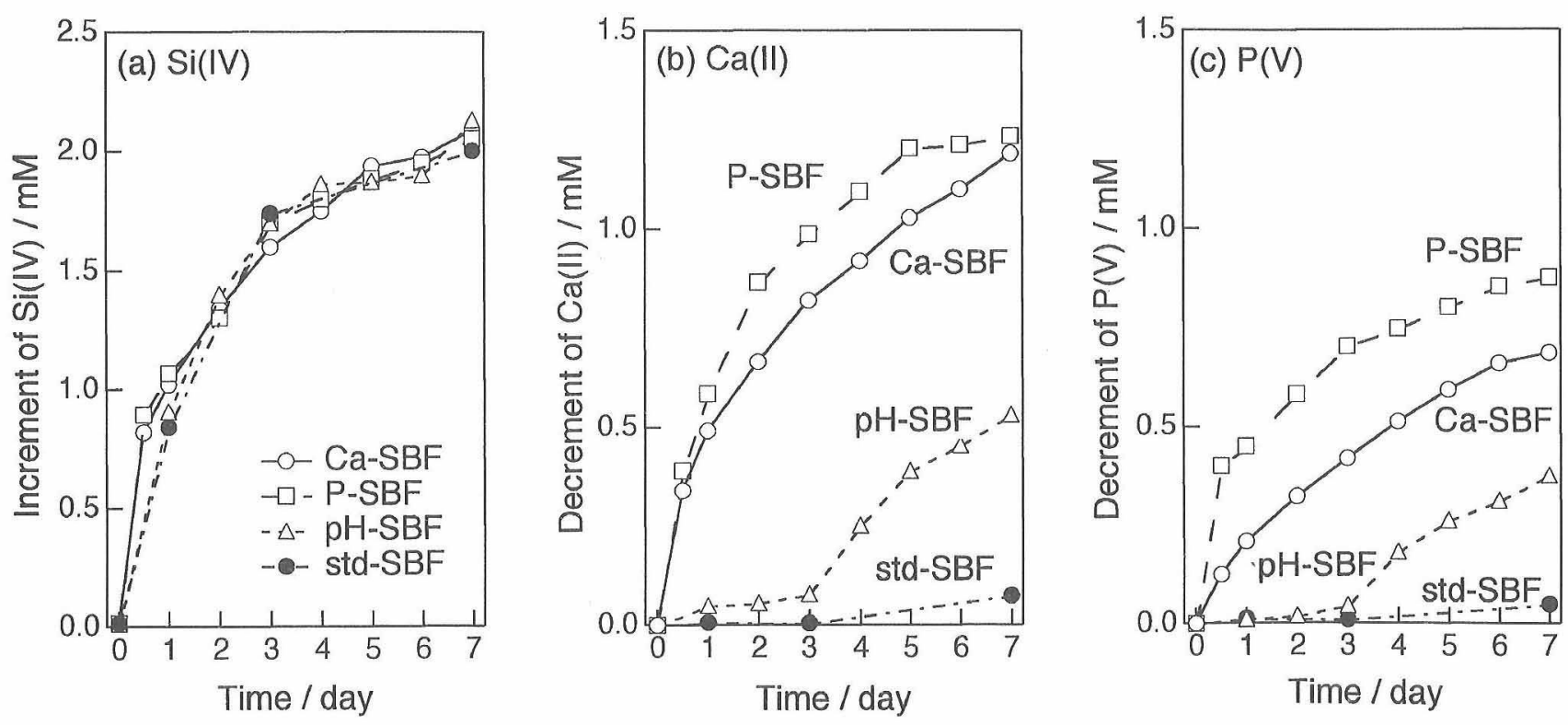

Fig. 2. Inorganic ion concentrations in Ca-SBF, P-SBF, pH-SBF and std-SBF; (a) the increase of $\mathrm{Si}$ (IV), (b) the decrease of Ca(II), and (c) the decrease of $\mathrm{P}(\mathrm{V})$. 


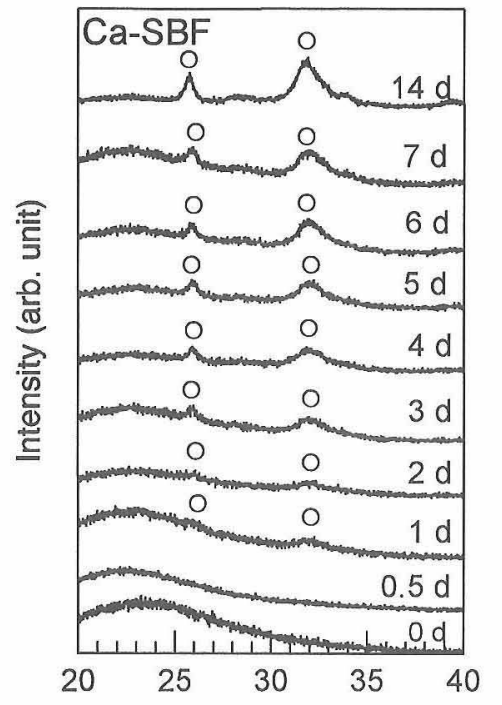

Diffraction Angle, $2 \theta /^{\circ}(\mathrm{Cu} \mathrm{K} \alpha)$

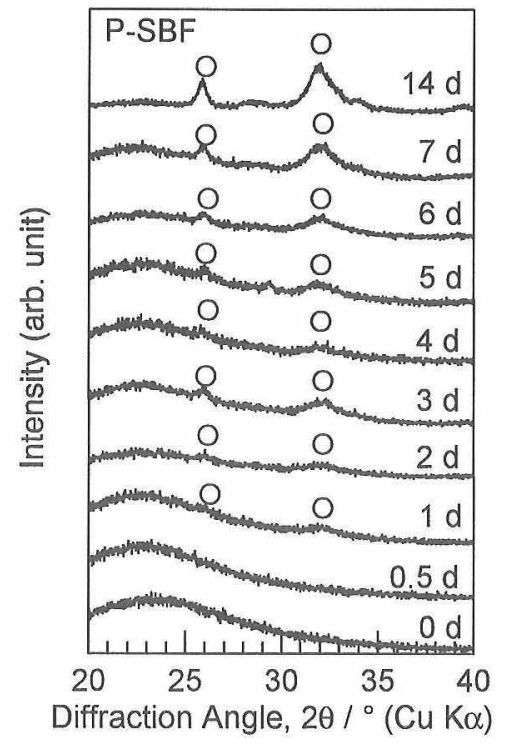

Fig. 3. Thin film X-ray diffraction for the silica gel after soaking for up to $14 \mathrm{~d}$ in Ca-SBF, P-SBF, pH-SBF and std-SBF. O Apatite

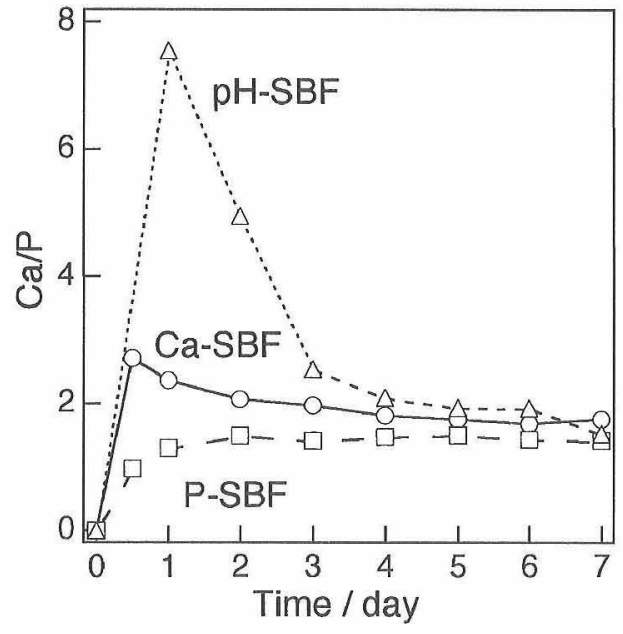

Fig. 4. Ratio $\mathrm{Ca} / \mathrm{P}$ of calcium phosphate deposited in $\mathrm{Ca}-\mathrm{SBF}$, $\mathrm{P}-\mathrm{SBF}$ and $\mathrm{pH}-\mathrm{SBF}$ on the silica gel surface as the function of soaking period.

pores was $78 \%$ and the rest was for mesopores at first. Those values agree well with the original ones. ${ }^{9)}$ The pore size distribution changed slightly within $1 \mathrm{~d}$, however, no further changes in pore distribution was observed up to $7 \mathrm{~d}$. Figures 6 and 7 indicated that the silicate units in gel surface were rearranged within $1 \mathrm{~d}$ soaking.

\section{Discussion}

4.1 Apatite nucleation and crystal growth

Induction time for apatite deposition has been derived in a few ways. For example, it has been assigned to the period before $\mathrm{P}-\mathrm{O}$ vibration appears in FT-IR spectra ${ }^{18)}$ or to the period before $\mathrm{Ca}(\mathrm{II})$ or $\mathrm{P}(\mathrm{V})$ concentration starts decreasing. ${ }^{9), 13)}$ However, the induction time from these methods means the time needed for deposition of detectable amount of calcium phosphates that are not necessarily apatite but could be amorphous calcium phosphates (ACP). In this study, a new method is proposed. One can assume that the apatite peak area in the TF-XRD pattern is propor- tional to the amount of apatite deposited under the same measuring conditions. Thus the period before the apatite diffractions appear is to be assigned to the induction time. With the nucleation-growth theory, the induction time corresponds to the time when the nuclei has grown to yield apatite much enough to give detectable signals of X-ray diffractions. Thus the increment of the peak area versus time curve gives the apatite crystal growth rate.

In the XRD peaks for apatite appearing around $26^{\circ}$ and $32^{\circ}$, the $26^{\circ}$ peak is the (002) diffraction and while the $32^{\circ}$ one is an envelope of (211), (112) and (300) diffractions. In the present study, the former peak was selected for simplicity to evaluate the induction time for the growth along the $c$ axis. The peak area of the (002) diffraction was obtained by linear background subtraction in the range from $24.9^{\circ}$ to $26.7^{\circ}$ and was plotted in Fig. 8(a) as a function of the soaking period. The plots were fitted with smooth curves. The induction time was assigned to the period of time at which the curve crossed the $x$-axis. Table 3 summarized both induction times and actual values of IAP determined by ICP-AES measurement. The induction time increased in the order;

[the induction time]

$$
\begin{aligned}
& \text { Ca-SBF }(5.4 \mathrm{~h})<\mathrm{P}-\mathrm{SBF}(16.1 \mathrm{~h}) \ll \mathrm{pH}-\mathrm{SBF} \\
& (2.44 \mathrm{~d})<\text { std-SBF }(>14 \mathrm{~d})
\end{aligned}
$$

The result indicated that the increase of $\mathrm{Ca}(\mathrm{II})$ and $\mathrm{P}(\mathrm{V})$ ion concentration was much more effective for apatite nucleation and that of $\mathrm{OH}^{-}$was least effective among the three species. Within 4-7 d of soaking, the peak area for P-SBF did not increase so much as that for $\mathrm{Ca}-$ and $\mathrm{pH}-\mathrm{SBF}$. It follows that P-SBF less favored the apatite growth despite of inducing faster nucleation. The XRD intensity for Ca-, P-, and $\mathrm{pH}-\mathrm{SBF}$ seemed being saturated in longer soaking. This was accountable as showing that the ionic components of apatite in SBF's were being exhausted due to apatite deposition. Such exhaustion could thus well discriminate the ability of each SBF to bring the apatite crystallization. Thus the data for the initial stages, maybe within two or three days, should deserve further discussion.

The peak area curves were differentiated with the soaking period to yield differential crystal curves as a function of soaking period, shown in Fig. 8(b), which represented the rate of apatite crystal growth. The curves in Fig. 8(b) com- 
Table 2. Fraction of $Q^{n}$ Unit in the Silica Gels after Soaking Derived the ${ }^{29} \mathrm{Si}$ CP-MAS-NMR Spectra. Gels were Soaked in the Saline Solution

\begin{tabular}{|c|c|c|c|c|c|c|c|c|c|}
\hline \multirow[b]{2}{*}{$\begin{array}{l}\text { Soaking } \\
\text { period (d) }\end{array}$} & \multicolumn{3}{|c|}{$Q^{2}$} & \multicolumn{3}{|c|}{$Q^{3}$} & \multicolumn{3}{|c|}{$Q^{4}$} \\
\hline & $\begin{array}{c}\text { Peak position } \\
\delta_{\text {iso }}(\mathrm{ppm})\end{array}$ & $\begin{array}{c}\text { FWHM }^{\dagger} \\
\text { (ppm) }\end{array}$ & $\begin{array}{c}\text { Peak area } \\
(\%)\end{array}$ & $\begin{array}{c}\text { Peak position } \\
\delta_{\text {iso }}(\mathrm{ppm})\end{array}$ & $\begin{array}{c}\mathrm{FWHM}^{\dagger} \\
(\mathrm{ppm})\end{array}$ & $\begin{array}{c}\text { Peak area } \\
(\%)\end{array}$ & $\begin{array}{c}\text { Peak position } \\
\delta_{\text {iso }}(\mathrm{ppm})\end{array}$ & $\begin{array}{l}\text { FWHM' } \\
\text { (ppm) }\end{array}$ & $\begin{array}{c}\text { Peak area } \\
(\%)\end{array}$ \\
\hline 0 & -91.7 & 5.5 & 19.8 & -100.7 & 6.0 & 59.3 & -110.1 & 8.5 & 20.9 \\
\hline 1 & -91.6 & 4.6 & 15.9 & -101.1 & 5.2 & 70.2 & -111.0 & 6.0 & 13.9 \\
\hline 7 & -91.8 & 4.5 & 12.4 & -101.1 & 5.4 & 70.2 & -110.7 & 6.1 & 17.4 \\
\hline
\end{tabular}

†Full width at half maximum

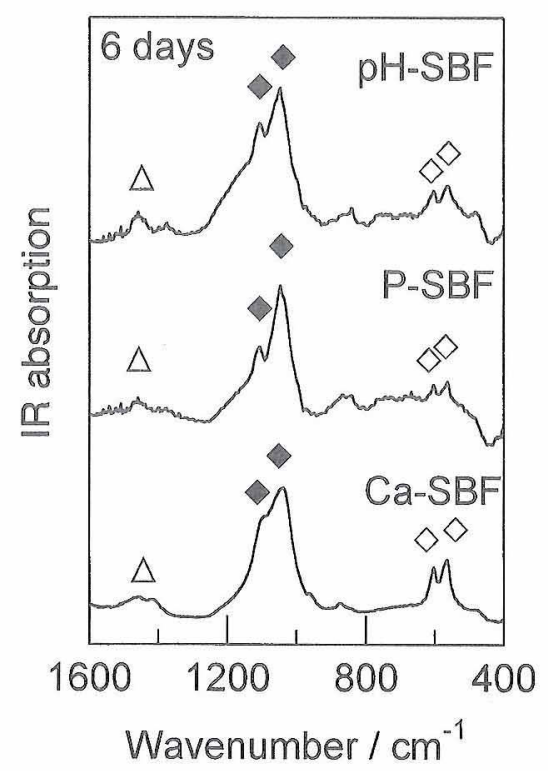

Fig. 5

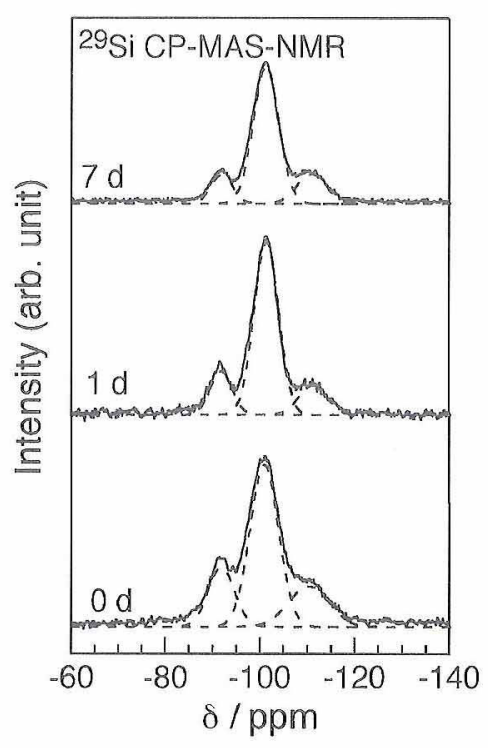

Fig. 6

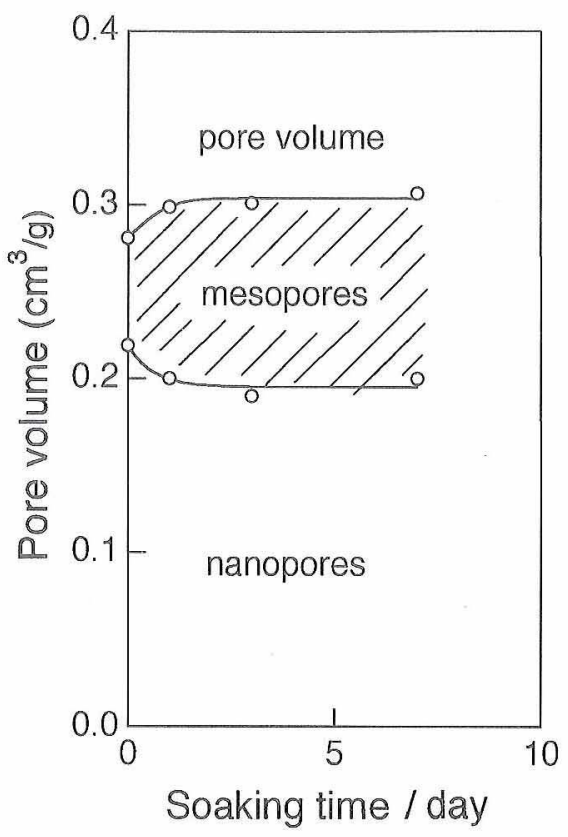

Fig. 7

Fig. 5. Difference FT-IR spectra for apatite particle formed on the silica gel after soaking in SBF's for $6 \mathrm{~d} . \diamond v(\mathrm{P}-\mathrm{O}), \diamond \sigma(\mathrm{P}-\mathrm{O})$, $\triangle v\left(\mathrm{CO}_{3}{ }^{2-}\right)$

Fig. 6. ${ }^{29} \mathrm{Si} \mathrm{CP}-\mathrm{MAS}-\mathrm{NMR}$ spectra of the silica gel before and after soaking in saline for 1 and $7 \mathrm{~d}$.

Fig. 7. Pore volume distribution of the silica gel after soaking in the saline. The volume of mesopores increased with the soaking.
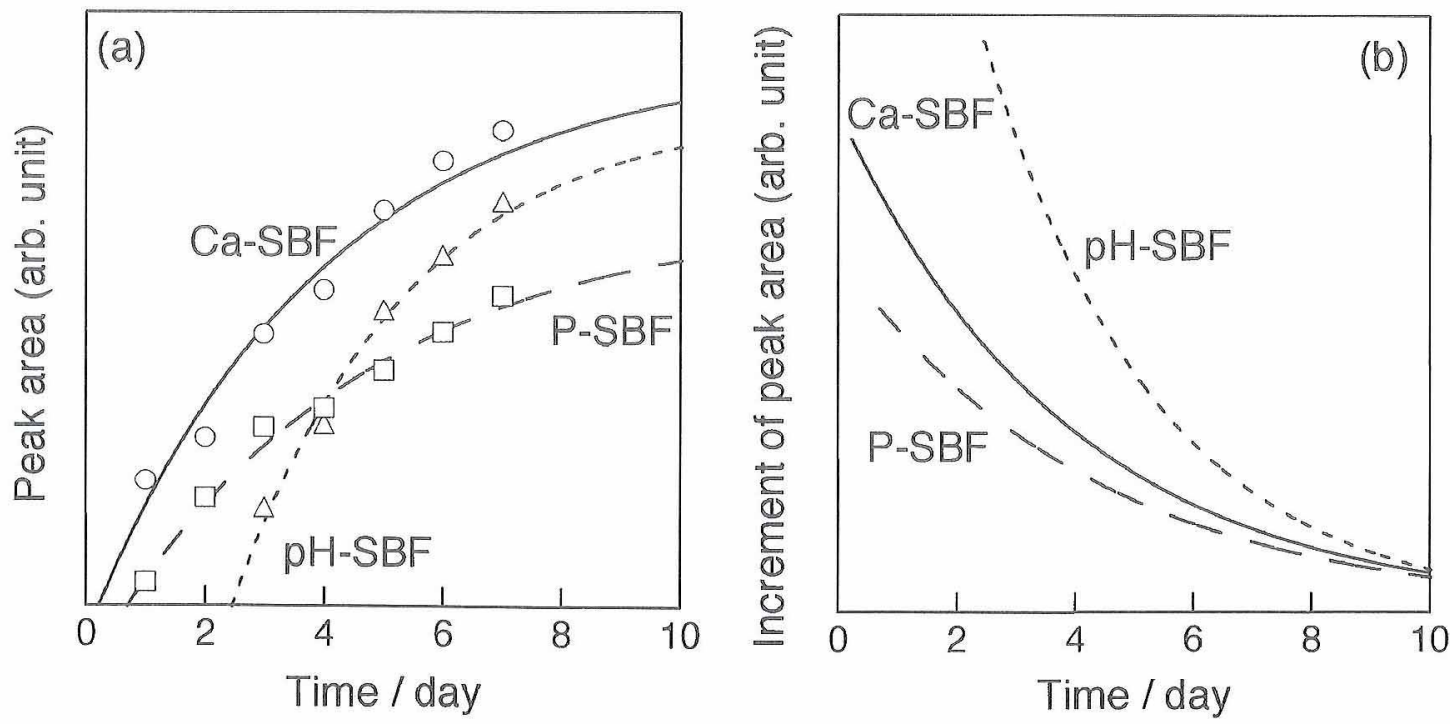

Fig. 8. (a) Peak area of (002) of apatite on the silica gel soaked in Ca-SBF, P-SBF and pH-SBF as a function of the soaking time. (b) Crystal growth rate of apatite in Ca-SBF, P-SBF and pH-SBF as a function of immersion time. 
Table 3. Induction Period of Apatite Nucleation and Measured IAP of Each SBF

\begin{tabular}{lcc}
\hline & Induction period (hour) & $\log$ IAP $^{*}$ \\
\hline Ca-SBF & 5.4 & -95.01 \\
P-SBF & 16.1 & -95.04 \\
pH-SBF & 58.6 & -95.02 \\
std-SBF & no apatite & -96.35 \\
\hline
\end{tabular}

* Derived from the measured ion concentration. Designed log IAP is -95.00 for $\mathrm{Ca}-\mathrm{P}$ - and $\mathrm{pH}-\mathrm{SBF}$ and is -96.56 for std-SBF.

pared the growth rate among the three SBF's. The growth rate increased in the order;

[the rate of initial crystal growth]

$\mathrm{P}-\mathrm{SBF}<\mathrm{Ca}-\mathrm{SBF}<\mathrm{pH}-\mathrm{SBF}$

This result indicated that the increase of $\mathrm{Ca}(\mathrm{II})$ and $\mathrm{OH}^{-}$ concentration was more effective for the initial crystal growth rate than that of $\mathrm{P}(\mathrm{V})$.

\subsection{Mechanism of apatite formation}

Contrary to the initial expectation, the three SBF's yielded differences in the amount of decrease in $\mathrm{Ca}(\mathrm{II})$ and $\mathrm{P}(\mathrm{V})$ (Fig. 2), induction time, and initial crystal growth rate (Fig. 8(b)). For interpretation of the results and elucidation of the mechanism of apatite deposition, note that $\mathrm{Ca}$ (II) and $\mathrm{P}(\mathrm{V})$ were deposited on the gel within the induction period but not gave any XRD peaks, as well demonstrated for $\mathrm{pH}-\mathrm{SBF}$. This indicates that amorphous calcium phosphates (ACP) deposited in SBF's on the samples as the precursor and were crystallized to apatite. Several studies reported that some calcium phosphates ${ }^{19)-21)}$ were detected in supersaturated solutions and they transformed into apatite nuclei. Thus Fig. 4 should be interpreted as indicating that Ca-rich ACP was deposited in $\mathrm{Ca}-\mathrm{SBF}$ and $\mathrm{pH}-\mathrm{SBF}$, and $\mathrm{Ca}$-poor $\mathrm{ACP}$ was deposited in P-SBF. In other words, the composition in the supersaturated solutions determines the composition of deposited ACP. Then the composition of $\mathrm{ACP}$ controls the rate of apatite nucleation and crystal growth as well as the amount of precipitation. In summary, Ca-rich ACP is favorable for apatite nucleation and crystal growth than Ca-poor ACP, whereas Ca-poor ACP is favorable for the greater amount of precipitation.

The increase of $\mathrm{OH}^{-}$accelerated the initial crystal growth of apatite (Fig. 8(b)). This result indicates the significance of $\mathrm{OH}^{-}$involvement in the growth of apatite as stressed by Hench and Andersson that ACP formed as the precursor of apatite nuclei and transformed into apatite nuclei by the incorporation of $\left.\mathrm{OH}^{-} .22\right)$ However, this also contradicts the fact that the induction time for $\mathrm{pH}-\mathrm{SBF}$ was longer than that for Ca-SBF and P-SBF. In Fig. 2, the smaller decrement in $\mathrm{Ca}(\mathrm{II})$ and $\mathrm{P}(\mathrm{V})$ in $\mathrm{pH}-\mathrm{SBF}$ indicates the deposition of a little amount of ACP. Thus, even if the samples were soaked in $\mathrm{pH}-\mathrm{SBF}$ with a higher concentration of $\mathrm{OH}^{-}$favoring the growth, the smaller number of the growth sites (ACP) should demand a longer induction time before apatite grew well enough to give detectable intensity of XRD. In contrast, the larger amount of ACP deposited in Ca- and P-SBF overrided their lower ability in apatite growth and shortened the induction time. The most significant change during the induction time was the increase in the fraction of unit $Q^{3}$ and decrease in that of $Q^{4}$ as the samples were soaked in the saline solution. This induces a rearrangement of the silicate units in the gel surface. A simi- lar change could be expected in the three SBF's because the primary ingredients in the SBF's were sodium and chloride ions. Moreover, like the phase modification of silica in the ceramics field, the rearrangement of the silicate units is difficult in the solidified gel state. As far as dissolution of $\mathrm{Si}$ (IV) was observed, deposition of the dissolved silicate units, regardless to being in the form of single $\mathrm{SiO}_{4}{ }^{-}$units or that of oligomers, took place as the reverse reaction. In the liquid phase the silicate units may experience further hydrolysis to smaller units or recondensation, and all of them can diffuse anywhere almost freely to be condensed with the silicates in the gels. Therefore, the rearrangement involving dissolution of $\mathrm{Si}$ (IV) takes place during the induction time, and at the same time, ACP deposits. Such a model agrees well with the previous report that apatite formation was induced by the rearrangement of silicate units in the silica gel layer formed on a sodium silicate glass when it was soaked in std-SBF. ${ }^{23)}$

Thus derived mechanism of apatite nucleation is illustrated in Fig. 9. The increase of $\mathrm{Ca}(\mathrm{II})$ and $\mathrm{P}(\mathrm{V})$ ion concentration in SBF induces the deposition of $\mathrm{ACP}$ as the precursor of apatite nuclei and ACP's transform into apatite nuclei by the incorporation of $\mathrm{OH}^{-}$. The transformation is assisted by both a large amount of ACP and the rearrangement of silicate units in the silica gel surface. Ca-poor ACP is unfavorable for apatite nucleation and crystal growth.

\section{Conclusion}

The porous silica gel derived by sol-gel process induced biomimetic apatite formation in the modified SBF's, which were prepared to be rich in each of $\mathrm{Ca}(\mathrm{II}), \mathrm{P}(\mathrm{V})$, and $\mathrm{OH}^{-}$ ions and to have the same supersaturation ratio. The increases of $\mathrm{Ca}(\mathrm{II})$ and $\mathrm{P}(\mathrm{V})$ ion concentration accelerated apatite nucleation and the increase of $\mathrm{OH}^{-}$ion concentration accelerated the apatite crystal growth. We could explain these results by the assumption of $\mathrm{ACP}$ as a precursor of apatite nuclei and ACP transformed into apatite by the incorporation of $\mathrm{OH}^{-}$. This transformation was accelerated by the larger number of the growth sites (ACP) and was assisted by the structure rearrangement of silicate units in the gel surface. The composition of ACP depended on the composition in the saturated solution, thus Ca-rich ACP was formed in calcium- and hydroxide-rich SBF. Ca-rich ACP was more favorable for apatite nucleation and crystal growth than Ca-poor ACP formed in phosphate-rich SBF.

Acknowledgment Satoshi Hayakawa is grateful of the financial support of Mazda Foundation. We are grateful to the SS-NMR Division of the VB Laboratory of Okayama University for ${ }^{29} \mathrm{Si}$ MAS-NMR experiments. Helpful discussion with Dr. Kazuki Nakanishi is also acknowledged.

\section{References}

1) Hench, L. L., Splinter, R. J. and Allen, W. C., J. Biomed. Mater. Res., 2, 117-41 (1973).

2) Andersson, Ö. H., Karlsson, K. H. and Kangasniemi, K., J. Non-Cryst. Solids, 119, 290-96 (1990).

3) Ohtsuki, C., Kobayashi, Y., Tsuru, K. and Osaka, A., J. Soc. Mat. Sci. Jpn., 44, 693 (1995).

4) Kokubo, T., Kushitani, H., Sakka, S., Kitsugi, T. and Yamamuro, T., J. Biomed. Mater. Res., 24, 721-34 (1990).

5) Emerson, W. H. and Fischer, E. D., Arch. Oral. Biol., 7, 671-83 (1962).

6) Baxter, J. D. and Pellegrino, R. M., Yale J. Biol. Med., 3, 456-70 (1966).

7) Hench, L. L. and Wilson, J., "An Introduction to Bioceramics," Ed. by Hench, L. L. and Wilson, J., World Scientific, London (1993) p. 8.

8) Ohtsuki, C., Kokubo, T. and Yamamuro, T., J. Non-Cryst. Solids, 14, 84-92 (1992).

9) Li, P., Ohtsuki, C., Kokubo, T., Nakanishi, K., Soga, N., 

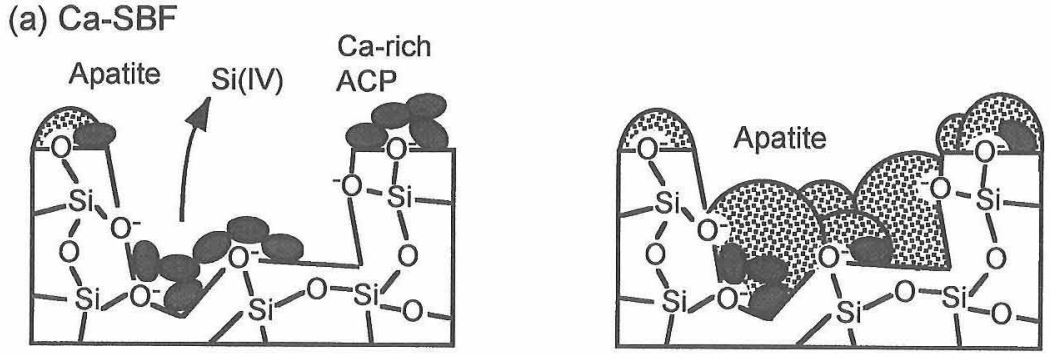

(b) P-SBF
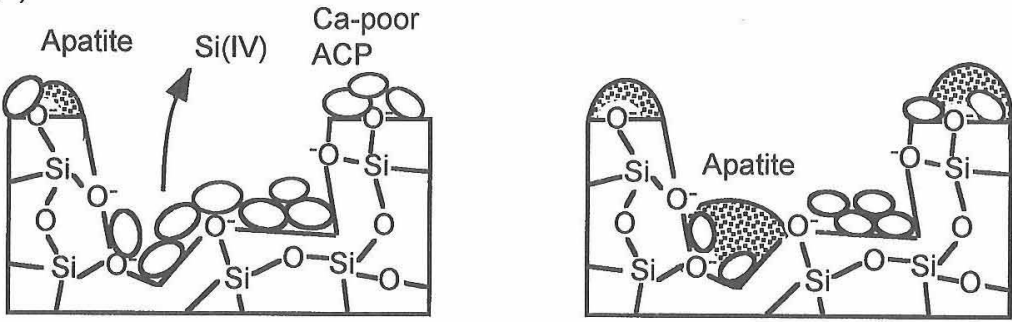

(c) $\mathrm{pH}-\mathrm{SBF}$

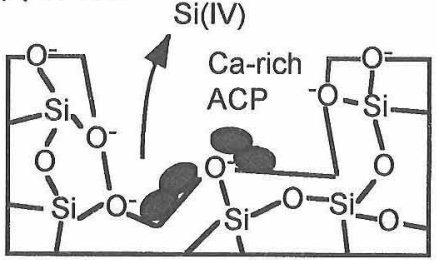

Ca-rich
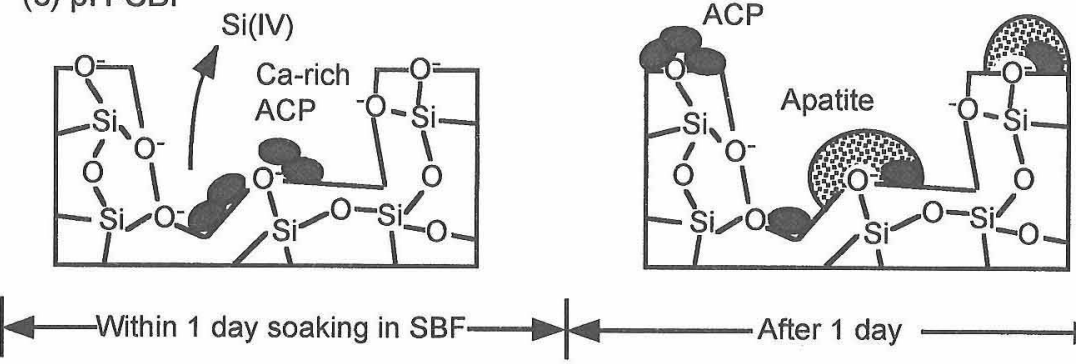

Fig. 9. Illustration of apatite nucleation on the silica gel surface in (a) Ca-SBF, (b) P-SBF and (c) pH-SBF. With deposition of a large amount of ACP, the gel structure is easily reorganized. Then, ACP transforms into apatite nuclei by the incorporation of $\mathrm{OH}^{-}$. Since more $\mathrm{ACP}$ deposits in (a) and (b), this process is easier in (a) and (b) than (c). Calcium-rich ACP in (a) and (c) accelerates the transformation whereas calcium-poor ACP in (b) is reluctant to crystallize into apatite.

Nakamura, T. and Yamamuro, T., J. Appl. Biomat., 4, 221-29 (1993).

10) Damen, J. J. M. and Cate, J. M., J. Dent. Res., 68, 1355-59 (1989).

11) Nancollas, G. H., "Biomineralization," Ed. by Mann, S., Webb, J. and Williams, R. J. P., VCH publishers, New York (1989) pp. 159-65.

12) Neuman, W. and Neuman, N., "The Chemical Dynamics of Bone Mineral," University of Chicago, Chicago (1958) p. 7.

13) Li, P., Ohtsuki, C., Kokubo, T., Nakanishi, K., Soga, N., Nakamura, T. and Yamamuro, T., J. Am. Ceram. Soc., 75, 2094-97 (1992).

14) Nakanishi, K., J. Porous Mater., 4, 67-112 (1997).

15) Rey, C., Cooins, B., Goehl, T., Dickson, I. R. and Glimcher, M. J., Calcif. Tiss. Res., 45, 157-64 (1989).

16) Magi, M., Lippma, E., Samoson, A., Engelhardts, G. and
Grimmer, A. R., J. Phys. Chem., 88, 1518-22 (1984).

17) Maekawa, H., Maekawa, T., Kawamura, K. and Yokokawa, T., J. Non-Cryst. Solids, 127, 53-64 (1991).

18) Pereira, M. M., Clark, A. E. and Hench, L. L., J. Am. Ceram. Soc., 78, 2463-68 (1995).

19) Eanes, E. D., Gillessen, I. H. and Posner, A. S., Nature (London), 208, 365-67 (1965)

20) Walton, A. G., Bodin, W. J., Füredi, H. and Schwartz, A., Can. J. Chem., 45, 2695-701 (1967).

21) Nancollas, G. H. and Tomazic, B., J. Phys. Chem., 78, 2218-25 (1974).

22) Hench, L. L. and Andersson, Ö. H., "An Introduction to Bioceramics," Ed. by Hench, L. L. and Wilson, J., World Scientific, London (1993) p. 47.

23) Hayakawa, S., Tsuru, K., Ohtsuki, C. and Osaka, A., J. Am. Ceram. Soc., 82, 2155-60 (1999). 